\title{
Cooperação e Altruísmo no Segundo Ano de Vida e Crenças e Práticas Maternas: Um Estudo Exploratório
}

\author{
Luciana Fontes Pessôa \\ Pontificia Universidade Católica do Rio de Janeiro \\ Rio de Janeiro, RJ, Brasil \\ Maria Lucia Seidl-de-Moura \\ Deise Maria Leal Fernandes Mendes \\ Rafael Vera Cruz de Carvalho \\ Laura Cristina Stobäus \\ Universidade do Estado do Rio de Janeiro \\ Rio de Janeiro, RJ, Brasil
}

\begin{abstract}
RESUMO
A integração das perspectivas de trajetórias de socialização e manifestações iniciais de cooperação e altruísmo foi investigada neste estudo com 37 crianças (17-26 meses) e suas mães, que responderam a inventários de metas de socialização e de práticas parentais no primeiro ano. As crianças realizaram tarefas de cooperação (em duplas) e de altruísmo. Os resultados indicaram a valorização de um perfil de autonomia-relacionada pelas mães. Dentre as duplas, $44 \%$ apresentaram cooperação. Não foram observadas diferenças de idade entre as crianças que cooperam e as que não, ou com escores das mães nas variáveis estudadas. Foi encontrada uma correlação positiva entre metas relacionais e altruísmo. O estudo contribui para a literatura de desenvolvimento social no contexto.
\end{abstract}

Palavras-chave: Cooperação; Altruísmo; Infância.

\section{ABSTRACT}

Cooperation and Altruism in the Second Year and Maternal Beliefs: An Exploratory Study

The integration of the perspectives of socialization trajectories and early manifestation of cooperation and altruism was investigated in this study with 37 toddlers (17-26 months old) and their mothers, who fulfilled some questionnaires on socialization goals and parenting practices within the first year of age. Toddlers realized a cooperation task (in pairs), and altruism tasks. Results indicate mothers value an autonomous-related profile. Among the toddlers' pairs, $44 \%$ presented cooperation. It was not observed differences of age between toddlers who cooperated and those who did not, or between mothers' score in the studied variables. Positive correlation was found between relational goals and altruism. This study makes a contribution for the literature on social development in the context.

Keywords: Cooperation; Altruism; Childhood.

\section{RESUMEN}

Cooperación y Altruismo en el Secundo Año de Vida y Crenças y Prácticas Maternas: Un Estudio Exploratorio

La integración de las perspectivas de trayectorias de socialización y manifestaciones iniciales de la cooperación y del altruismo se investigo, en este estudio, en 37 niños ( 17 a 26 meses) y sus madres, que respondieron a los inventarios de metas de socialización y de prácticas parentales en el primer año. Los niños realizaron tareas de cooperación (en parejas) y de altruismo. Los resultados indicaron la valorización del perfil autónomo-relacional de las madres. Entre las parejas, $44 \%$ presentaron cooperación. No se observaron diferencias de edad entre los niños que cooperan y los que no lo hacen, tampoco com los scores de las madres en las variables estudiadas. Se ha encontrado una correlación positiva entre las metas relacionales y del altruismo. El estudio contribuye para la literatura del desarrollo social en el contexto.

Palabras clave: Cooperación; Altruism; Infância. 
A tendência a comportamentos altruístas (Warneken \& Tomasello, 2009) e a capacidade de cooperação são características presentes em nossa espécie e selecionadas na evolução (Tomasello, 2001). Atividades de cooperação são importantes para espécies sociais e apresentam determinadas particularidades em humanos. Cooperação é o conjunto de habilidades cognitivas e sociais que permite a coordenação do comportamento de um indivíduo com outro, de acordo com intenções conjuntas e visando metas comuns. Os mecanismos que envolvem a cooperação serviram e servem de base para criação de ferramentas, uso de sistemas simbólicos e para o funcionamento das instituições sociais ao longo da nossa história. Suas bases remontam ao nosso passado filogenético e as compartilhamos em parte com outros primatas, como chimpanzés (Tomasello, 2001).

A cooperação também pode ser relacionada ao altruísmo. Para Tomasello, Melis, Tennie, Wyman e Herrmann (2012), o altruísmo se liga à cooperação pela possibilidade de reciprocidade (inicialmente dentro de pequenos grupos de aparentados e, depois, em grupos cada vez maiores) e por tornar um grupo cooperativo com vantagem sobre grupos concorrentes. Os autores propõem a "hipótese da interdependência": colaborar foi necessário para sobreviver, na coordenação para adquirir comida e para competir com outros grupos. Nossos ancestrais formavam coalizões para competir pelos recursos e pela sua manutenção contra outras coalizões rivais. Dentro dessas coalizões, há o fortalecimento do senso de pertencimento ao grupo, o que pode ser relacionado pelo uso de artefatos e tradições culturais específicos ao próprio grupo.

O altruísmo é mensurado pela observação do comportamento de ajuda instrumental, que é aquele em que uma pessoa age de modo a ajudar outra a atingir um objetivo concreto. Esse comportamento apresenta componentes cognitivos e motivacionais. $\mathrm{O}$ aspecto cognitivo envolve a capacidade de reconhecimento da meta que o outro está tentando alcançar. A motivação está envolvida porque ajudar o outro pode ser custoso para si.

Para Warneken (2010), o desenvolvimento de motivações altruístas não é exclusivo dos seres humanos. $\mathrm{O}$ autor relata experimentos com crianças pequenas e chimpanzés que indicam que o altruísmo humano não se deve somente às práticas culturais, mas pode refletir predisposições biológicas que compartilhamos com chimpanzés.

\section{COOPERAÇÃO NA ONTOGÊNESE}

O comportamento cooperativo surge cedo no desenvolvimento humano e também pode ser observado em filhotes de chimpanzés, apesar de apresentarem algumas diferenças importantes. Chimpanzés têm sido amplamente estudados em tarefas de cooperação e estes estudos comparativos trazem algumas evidências que nos ajudam no entendimento da natureza da cooperação humana.

Alguns autores consideram que a cooperação se estabelece aos 18 meses de idade (Warneken \& Tomasello, 2007, 2009), porém suas bases surgem antes. Hamlin e Wynn (2011) mostraram que crianças de três, cinco e nove meses de idade parecem discriminar e apresentar preferência por fantoches parceiros de cooperação. As crianças olharam com maior frequência ou moveram as mãos para pegar (de acordo com a idade) fantoches cooperadores, aqueles que ajudavam outros, em detrimento dos que não ajudavam. Com um ano de idade, há evidências de formas primitivas de ação coordenada; aos 14 meses, as crianças engajam-se em atividades cooperativas iniciais; no fim do segundo ano, aparecem jogos imitativos e rotinas simples com uma meta comum; e no terceiro ano, a articulação de metas, papéis e ações toma forma (Warneken \& Tomasello, 2007; Warneken \& Tomasello, 2009).

Brownell, Ramani e Zerwas (2006) estudaram 88 crianças divididas em três grupos de idade, em média de 19, 23 e 27 meses. Foi utilizada uma tarefa de cooperação que exigia a ação conjunta de duas crianças para acionar um dispositivo. Dentre outros aspectos foi observado que as crianças mais velhas coordenaram suas ações com os parceiros mais do que as mais novas. As de 19 meses apresentaram o menor número de comportamentos cooperativos, seguidos pelos de 23 meses e pelos de 27 meses, todos com diferenças significativas. Esses resultados se mostraram associados ao desenvolvimento da compreensão social.

Alguns estudos confirmam os resultados de Brownell et al. (2006) e demonstraram especificidades do desenvolvimento humano em relação à cooperação. Warneken, Chen e Tomasello (2006) estudaram a cooperação de crianças (18 e 24 meses) em interação com adultos, assim como jovens chimpanzés. A tarefa utilizada envolvia que o experimentador simulasse interromper sua participação. Ambos os grupos de idade das crianças tentaram reengajar o experimentador na tarefa com gestos e, aos 24 meses, também verbalmente. Isso não ocorreu com os chimpanzés, que não tentaram reengajar o experimentador, não se mostraram tão interessados na tarefa quanto na meta e participavam mais com objetivo individual e concreto (principalmente alimento). Warneken, Gräfenhain e Tomasello (2012) obtiveram o mesmo resultado ao tentar reengajamento com crianças aos 27 meses. Os 
autores usaram jogos colaborativos do experimentador com as crianças. Este interrompia o jogo várias vezes, fingindo ser incapaz de terminar a tarefa, ou não desejar continuar. A criança levava em consideração o motivo do outro em não colaborar, tentando encorajar o experimentador a continuar quando este demonstrava ser incapaz de realizar a tarefa. Os resultados demonstraram que mesmo aos 27 meses as crianças já percebem o parceiro como colaborador quando interagindo com eles.

As evidências indicam, então, que a partir de uma base evolutiva de algumas habilidades iniciais, os primeiros comportamentos cooperativos começam a se estabelecer ao longo do segundo ano de vida e gradualmente se pode notar um aumento da complexidade desses comportamentos.

\section{ALTRUÍSMO EM CRIANÇAS PEQUENAS}

Há evidências de que as crianças em idade préescolar, e, mesmo mais cedo (com um/dois anos), mostram preocupação com outros em situação de estresse e buscam responder às necessidades emocionais de outros, por exemplo, confortando alguém que esteja chorando (Warneken \& Tomasello, 2006, 2007).

As manifestações de altruísmo são, aparentemente, precoces na infância podendo ser percebidas em crianças pequenas, por volta de 14 meses (Warneken \& Tomasello, 2007). Crianças de 14 a 18 meses exibem ajuda espontânea sem recompensa quando outra pessoa é incapaz de atingir seu objetivo (Warneken \& Tomasello, 2009).

Em estudo com crianças de 18 meses de idade através de diversas situações em que o experimentador não estava conseguindo atingir um objetivo, Warneken e Tomasello (2006) verificam que as crianças ajudam espontaneamente e sem serem recompensadas mais frequentemente. Isto demonstra uma capacidade de diferenciar entre atos acidentais e propositais e de ajudar de acordo com a necessidade. Além disso, em outro estudo, Warneken e Tomasello (2008) relatam que recompensas materiais parecem afetar a motivação intrínseca para a ajuda, tanto que crianças que receberam recompensas no início da sessão de atividades foram menos propensas a ajudar depois, se comparadas às que não receberam. Segundo Warneken e Tomasello (2009), crianças entre 12 e 18 meses entendem o comportamento dos outros em termos de metas subjacentes e intencionais e podem diferenciar entre uma ação proposital de uma acidental, ou seja, percebem se o apelo para uma ajuda tem uma intenção real.

Warneken (2010) defende que o aparecimento destes comportamentos tão cedo no desenvolvimento sugere que as normas sociais e morais não são sua fonte principal. Contra argumentos de que as crianças captam padrões culturais rapidamente e os pais poderiam estar estimulando comportamentos altruístas, ele pondera que se fosse assim, não encontraríamos as mesmas motivações altruístas em chimpanzés. À medida que ficam um pouco mais velhas, as crianças se tornam mais seletivas em sua ajuda, utilizam estratégias e se comportam nas situações de demanda de ajuda, de modo qualitativamente diferenciado. Além disso, também adquirem um senso de normas sociais, de regras de grupo a serem seguidas, ou seja, um senso de "nós devemos fazer assim", que Tomasello (2001) chama de "intencionalidade compartilhada". Essa capacidade permite às crianças formarem objetivos comuns e coordenarem atividades umas com as outras, não estando presente em chimpanzés juvenis. Estes animais, embora colaborativos de certo modo, não demonstram maior interesse no que pensam ou almejam seus companheiros. As intenções de cada indivíduo precisam ser apreendidas pelo outro, sendo incorporadas. Essas intenções conjuntas (planos) fazem com que os indivíduos se organizem em papéis interdependentes, visando uma meta comum.

Warneken (2013) apresenta experimentos para testar o comportamento de ajuda instrumental em crianças pequenas (de 21 a 30 meses), sem pistas do experimentador de que precisaria ser ajudado. Nos experimentos, o experimentador finge não perceber que uma das latas que ele arrumava de uma mesa para outra caiu. O experimentador continua arrumando as latas como se nada tivesse ocorrido para não dar pistas à criança, que brinca perto da mesa em que ocorreu a queda. Comparada à situação controle, em que o experimentador lança a lata ao chão, as crianças ajudaram mais, inclusive apontando e verbalizando sobre a queda da lata, o que também é um comportamento de ajuda, só que menos custoso. Assim, as crianças desta faixa etária parecem ser capazes de ajudar mesmo sem qualquer comportamento do experimentador que pudesse expressar a sua necessidade de ajuda. Crianças humanas parecem apresentar desde cedo a capacidade de inferir os objetivos dos outros, ampliando a gama de atividades em que agem colaborativamente.

Svetlova, Nichols e Brownell (2010) estudaram o comportamento prossocial em crianças de 18 e de 30 meses em três tipos de situações de ajuda a um adulto, envolvendo uma ajuda instrumental (baseada na conclusão de uma ação, com o experimentador tentando alcançar um objeto); empática (baseada na evitação de uma emoção negativa, com o experimentador simulando tristeza, frio e frustração); ou altruística (com custo para a criança - doação de algum objeto 
seu - e com objetivo de beneficiar o outro). Também foi avaliada a resposta das crianças, em função de necessitarem de mais ou menos indícios comunicativos do adulto a ser ajudado. Após um período de familiarização, uma experimentadora e uma assistente conduziram os testes em sessão única, em laboratório com espelho one-way. O experimento envolvia nove tarefas, três para cada tipo já citado, apresentando oito indícios comunicativos, progressivos em explicitar a necessidade de ajuda da experimentadora, o que gerou um "escore de ajuda" da criança, a partir da codificação da filmagem da sessão. Os autores discutem que, como esperado, o comportamento prossocial aumenta entre 18 e 30 meses. A ajuda instrumental foi mais fácil do que a ajuda empática e a altruística, especialmente para as crianças mais novas. Para eles, há uma transição no fim do segundo ano, quando os comportamentos de ajuda se ampliam para incluir a ajuda empática.

Em síntese, as evidências desses vários estudos levam-nos a supor que a metade do segundo ano de vida é um marco importante no desenvolvimento da cooperação e do altruísmo. O desenvolvimento conjunto desses dois aspectos não vem sendo investigado. Considera-se que isto seja necessário para oferecer um panorama mais amplo da relação entre cooperação e altruísmo. Além disso, acreditando que esse processo/ desenvolvimento se dá na relação com os outros (Schöre, 1994) pode-se hipotetizar que, apesar de universal, selecionado evolutivamente, assume formas e ritmos diversos de acordo com padrões de interação característicos de diferentes trajetórias de socialização. As origens dos comportamentos prossociais não são devidas totalmente à aprendizagem, mas ao longo do desenvolvimento, as propensões universais vão se tornando mais complexas e assumindo formas que são sensíveis ao contexto.

\section{DESENVOLVIMENTO EM TRAJETÓRIAS DE SOCIALIZAÇÃO}

Keller (2007) discute como as experiências interacionais diferem desde o nascimento, seguindo um curso próprio a partir e com base na sequência de interações mãe-bebê, e estabelecem trajetórias de desenvolvimento de selves distintas. Três desenlaces desse processo são um self mais autônomo e independente, um self interdependente e um self autônomo-relacionado. Estas modalidades possíveis hipotetizadas por Keller (2007) são derivadas dos modelos diferenciados de contato/cuidado de pais frente a seus filhos. Na primeira, é privilegiada a autonomia, compreendendo independência e separação de outros selves, marcado por um tipo de relacionamento distal em relação a outras pessoas. A segunda modalidade de trajetória, interdependente ou relacional, privilegia a heteronomia e a relação, caracterizando um tipo de relacionamento proximal. Na terceira, autônomorelacionada, são priorizadas de modo equilibrado, tanto a autonomia, quanto a relação.

Seidl-de-Moura, Carvalho e Vieira (2013) apresentam e discutem evidências de pesquisas brasileiras sobre esses modelos com mães de 16 contextos distintos de todas as regiões do país, com coletas realizadas em capitais e cidades do interior. Os resultados obtidos a partir de diferentes metodologias apontam para a predominância de um modelo de autonomiarelacionada nesses contextos. Foi verificado que a dinâmica de valorização de autonomia e relação está associada a características sociodemográficas dessas amostras (variados níveis de urbanização, diversas influências culturais predominantes e níveis de ensino). Mais recentemente, estudo longitudinal brasileiro em que foi analisado o envelope narrativo de mães residentes no Rio de Janeiro relata evidência similar (Mendes \& Seidl-de-Moura, 2013). Análises da fala das mães direcionadas aos seus bebês, observadas ao longo dos primeiros seis meses de vida destes, indicam uma valorização tanto de autonomia quanto um relacionamento proximal.

O presente trabalho pretende integrar essas duas perspectivas, que são consideradas complementares, buscando testar as diferenças dentro da universalidade: a de trajetórias de socialização e a do desenvolvimento da cooperação e do altruísmo. Considerando a ausência de estudos que contemplem o desenvolvimento inicial da cooperação, sua relação com o altruísmo e com características do contexto, esse estudo visa abordar essa lacuna da literatura e atingir o seguinte objetivo: analisar, em população do Rio de Janeiro, tendências maternas de valorização de trajetórias de desenvolvimento de selves mais voltadas para autonomia e/ou para relação e a capacidade de cooperação e altruísmo de seus filhos no segundo ano de vida, demonstradas em tarefas específicas.

Consideramos que este estudo tem um caráter exploratório, mas ele é orientado por algumas hipóteses. Com base na literatura brasileira (Seidl-de-Moura et al., 2013), (1) espera-se que as mães apresentem características de valorização equilibrada de autonomia e de interdependência. Com base na literatura de outros países (ex. Brownell et al., 2006; Svetlova, Nichols, \& Brownell, 2010) e o caráter universal desses comportamentos, (2) espera-se que as crianças apresentem comportamentos iniciais de cooperação (3) e que sejam capazes de discriminar situações em que sua ajuda é ou não necessária. (4) Finalmente, com 
base na relação biologia-cultura (Keller, 2007), esperase que haja relação entre os tipos de crenças maternas e o desempenho das crianças nas tarefas de cooperação e altruísmo.

\section{MÉTODO}

\section{Participantes}

Participaram do estudo 36 crianças do Rio de Janeiro (23 meninas e 13 meninos), que frequentavam três creches na cidade do Rio de Janeiro (duas particulares e uma filantrópica). Eram predominantemente de 20 a 24 meses de idade $(59,5 \% ; M=22,05$, $D P=1,4), 13,5 \%$ tinha até 19 meses $(M=18,2$; $D P=0,85)$ e $27 \%$ delas tinha mais de 25 meses $(M=25,3 ; D P=0,48)$. As mães participantes tinham entre 23 e 41 anos $(M=32$ anos; $D P=4,6)$ e as crianças tinham entre 17 e 26 meses $(M=22,41 ; D P=2,48)$. As mães se distribuíram por três níveis de escolaridade: até ensino médio incompleto $(N=7 ; 19 \%)$, até curso superior incompleto $(N=10 ; 27 \%)$, e pelo menos curso superior completo $(N=20 ; 54 \%)$.

\section{Instrumentos e tarefas}

PARA AS MÃES:

Foramutilizados: Inventário demetas de socialização e Inventário de práticas parentais no primeiro ano. Essas escalas foram traduzidas e adaptadas para português a partir de versões em inglês utilizados por Keller, Lamm, Abels, Yovsi, Borke, Jensen et al. (2006).

\section{Inventário de metas de socialização}

Consiste em uma lista de frases que indicam opiniões sobre metas que os pais vão tentar alcançar no desenvolvimento de seus filhos durante seus primeiros três anos de idade, que são lidas uma de cada vez. Pede-se à pessoa que indique se concorda ou não, em uma escala de 1 (se não concorda nem um pouco) a 5 (se concorda totalmente), reagindo espontaneamente, sem pensar muito. A análise fatorial de componentes principais produziu duas dimensões (Keller et al., 2006): de metas de autonomia (cinco itens), como "desenvolver competitividade", e relacionais (cinco itens), como "obedecer aos mais velhos". As subescalas das duas dimensões apresentaram índices adequados de fidedignidade (considerando a amostra total, Alfas de Cronbach de 0,93 para a subescala de metas de autonomia e 0,88 para a de metas relacionais). As duas medidas não se correlacionaram significativamente.

\section{Inventário de práticas parentais no primeiro ano}

Consiste em uma lista de dez frases sobre como é a maneira correta de uma mãe lidar com seu bebê ou filho pequeno. Diz-se à entrevistada que algumas coisas podem ser mais familiares do que outras e que talvez concorde com algumas das frases e não concorde com outras. Pede-se que imagine um bebê de mais ou menos três meses de idade e diga se concorda ou não, em uma escala de 1 (se não concorda nem um pouco) a 5 (se concorda totalmente), reagindo espontaneamente, sem pensar muito. Exemplos de itens são: Deve-se deixar que os bebês chorem um pouco para ver se eles se consolam sozinhos; Um bebê deve sempre estar perto de sua mãe, para que ela possa reagir imediatamente a seus sinais. As metas são classificadas em duas dimensões: autonomia (cinco itens) e relacionais (cinco itens). Os índices de fidedignidade são respectivamente 0,78 e 0,86 para as duas dimensões.

\section{PARA AS CRIANÇAS:}

Tarefa de cooperação

Essa tarefa foi adaptada de Brownell et al. (2006). Nela, um aparato especial foi utilizado. Trata-se de uma caixa de madeira azul medindo $100 \mathrm{~cm} \times 40 \mathrm{~cm} \times 30 \mathrm{~cm}$, com duas portinhas que abriam e fechavam através de alças a elas presas. Cada porta tinha uma alça, da mesma cor da caixa. As alças estavam colocadas no aparato um pouco abaixo da altura aproximada do ombro das crianças. A caixa era posicionada em cima de uma mesa de aproximadamente $40 \mathrm{~cm}$ de altura. Preso à parte superior (topo) da caixa havia um pequeno abajur infantil com o personagem Mickey, posicionado atrás de um anteparo de plástico branco transparente. Este abajur era acionado sempre que as duas portinhas eram abertas simultaneamente, fazendo com que a lâmpada acendesse e ficasse piscando (vide Figura 1). Para tornar a tarefa de cooperação (ação conjunta) as alças eram colocadas a uma distância uma da outra que não permitia que uma criança pequena pudesse puxá-las ao mesmo tempo e separadas por um anteparo transparente.

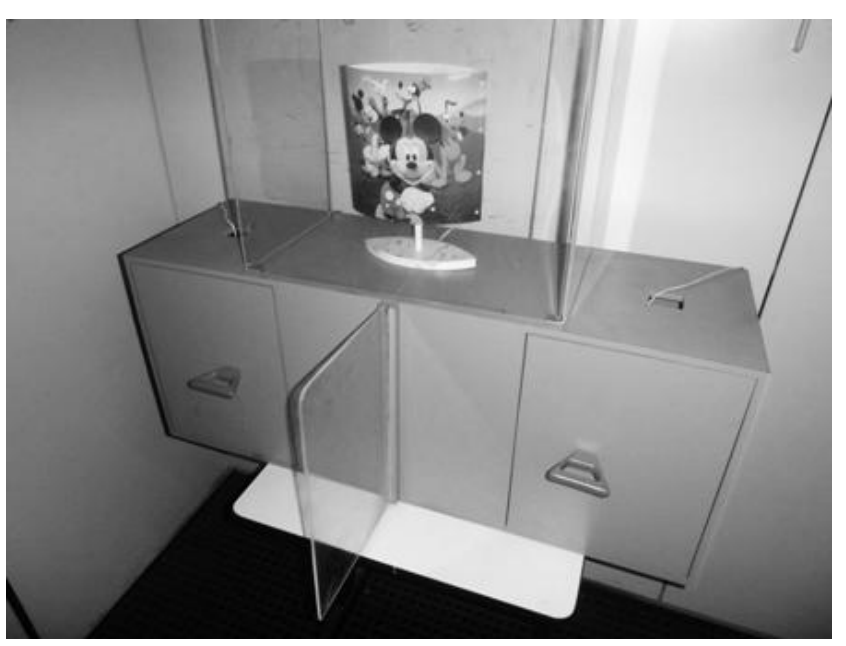

Figura 1. Aparato utilizado na tarefa de cooperação. 
Para a realização da tarefa, foram formadas 18 duplas. As crianças eram convidadas a participar de cada vez. A caixa era colocada em uma mesa com a altura especificada, de modo que as alças ficavam ao alcance fácil das crianças. $\mathrm{O}(\mathrm{A})$ experimentador(a) demonstrava a abertura simultânea das portas puxando as duas alças, dizendo: "Olhem, quando vocês puxarem juntos o Mickey vai piscar". Quando feito isso, era acionado o brinquedo. A demonstração era feita três vezes sucessivas e as crianças eram encorajadas a tentar. Neste estudo, as crianças deviam puxar as alças simultaneamente (com intervalo de menos de três segundos uma da outra). Quando esse critério era atingido, o abajur era ativado. O comportamento das crianças era observado durante 10 minutos para cada dupla. Dois tipos de escore eram obtidos. No primeiro, apenas a primeira tentativa era usada para categorizar as respostas. No segundo, a frequência de ações coordenadas era contabilizada e a frequência relativa ao tempo, calculada. As sessões eram gravadas em vídeo.

As respostas foram codificadas, segundo definições prévias estabelecidas para esse estudo, como: atividade não coordenada; atividade coordenada dirigida; atividade coordenada espontânea.

\section{Tarefa de altruísmo}

Foi utilizada uma versão adaptada da tarefa de Warneken e Tomasello (2006). Foram planejados dois cenários em que o pesquisador evidenciava precisar de ajuda. No primeiro, ele fingia estar arrumando brinquedos em uma caixa e os deixava cair. No segundo, deixava cair uma bola dentro de uma caixa e fingia não conseguir pegá-la. Eram realizadas 10 tentativas para cada cenário. Como situação de controle, para metade dos participantes eram jogados no chão lápis (10 vezes) e bolas em uma caixa (10 vezes), antes de realizar a tarefa em que se esperava ajuda. Para a outra metade, essa tarefa de controle era feita após a de teste. Foi registrada a frequência de comportamentos de ajuda em cada um dos dois cenários e a frequência dos comportamentos de pegar os objetos nas situações de controle.

\section{Procedimentos éticos}

O projeto foi submetido à Comissão de Ética em Pesquisa Psicológica da UERJ e foi aprovado (protocolo COEP 019/2008). Todas as mães participantes receberam informações orais e escritas sobre objetivos da pesquisa, responsabilidades do pesquisador, método empregado e direito a recusar o consentimento. A inclusão na amostra foi condicionada à assinatura do termo de consentimento livre e esclarecido.

\section{Procedimentos de coleta de dados}

A coleta de dados ocorreu em idas a campo e constou de atividades com as mães e com as crianças. Foram feitos contatos com creches, que se incumbiram de obter consentimento, se concordassem, com as famílias das crianças participantes. Nesse contato era marcado um encontro para que fossem fornecidas informações a respeito do projeto e apresentado o termo de consentimento para assinatura dos que se dispusessem a participar. A coleta foi feita nas creches, em locais indicados pela coordenação da instituição, solicitando-se a presença de educador da creche, responsável pelas crianças participantes. Os questionários foram enviados às mães para preenchimento e recolhidos, posteriormente, pela equipe de pesquisa.

\section{Procedimentos de redução e análise de dados}

Os instrumentos aplicados nas mães foram codificados e transcritos para uma planilha geral de dados. Os resultados relativos aos instrumentos de etnoteorias parentais foram utilizados para classificar as mães quanto à valorização de trajetórias de desenvolvimento que priorizem a autonomia, a relação ou ambas as necessidades de modo equilibrado. Os vídeos das sessões em que foram realizadas as tarefas com as crianças foram codificados para cada uma das tarefas/variáveis (cooperação - nível e frequência; e altruísmo - frequências dos comportamentos-alvo). Essa codificação foi feita, segundo as categorias acima apresentadas, por avaliadores que desconheciam a classificação das mães nas duas categorias a elas associadas. A fidedignidade foi avaliada entre dois codificadores que examinaram, independentemente, $30 \%$ dos vídeos.

A análise dos dados incluiu, além da estatística descritiva, testes $t$ pareados para testar diferenças entre as médias dos escores de metas voltadas para autonomia e para a relação, assim como para testar diferenças entre médias dos escores de práticas de autonomia e relacionais. Para examinar a relação entre os escores de práticas, metas de socialização e nível de escolaridade das mães, e também entre os de práticas de autonomia e práticas relacionais foram realizadas análises correlacionais. Os efeitos do nível de escolaridade das mães sobre as médias de práticas e metas de autonomia e relacionais foram testados através de ANOVA e testes post hoc. 


\section{RESULTADOS E DISCUSSÃO}

\section{Crenças e práticas maternas}

A primeira hipótese foi confirmada parcialmente. Tal como nos estudos brasileiros anteriores, não foram encontradas diferenças entre as médias das mães em metas relacionais e de autonomia, indicando a valorização de um perfil de autonomia-relacionada (Seidl-de-Moura, Carvalho, \& Vieira, 2013). No entanto, práticas de autonomia $(M=3,57, D P=0,70)$ foram mais valorizadas pelas mães do que práticas relacionais $(M=3,16, D P=0,67), t(36)=2,22$; $p<0,05)$. Assim, o perfil de autonomia-relacionada revela-se nas metas a longo prazo para seus filhos. Quando inquiridas sobre suas crenças sobre práticas, no entanto, as mães mostraram-se mais inclinadas a valorizar autonomia. Complementando esse resultado sobre a dinâmica entre a valorização de autonomia e relação/interdependência, foi encontrado um efeito significativo da escolaridade das respondentes sobre as suas médias em práticas relacionais, $F(2,34)=3,91, p<0,05$. Testes post-hoc indicaram diferenças significativas nos escores de mães até o ensino médio incompleto e as que tinham pelo menos o superior completo. Mães com menos escolaridade $(M=3,68, D P=0,91)$ valorizaram mais práticas relacionais do que as mães com mais anos de escolaridade $(M=2,93, D P=0,47)$. $\mathrm{O}$ mesmo não ocorreu com metas.

\section{Cooperação}

A maioria das crianças apresentou o comportamento de abrir o aparato $(72,9 \%)$, sendo voltado $(37,8 \%)$ ou não $(35,1 \%)$ para o parceiro. Somente 10 crianças não tiveram nenhuma reação. Os resultados acompanham, em parte, as evidências da literatura (Bronwell et al., 2006; Warneken \& Tomasello, 2007, 2009). Neste grupo, foi observada atividade coordenada em $44 \%$ das duplas, algumas delas de forma espontânea e em outras após incentivo do experimentador. Nesse sentido, a segunda hipótese foi parcialmente corroborada. As crianças apresentaram comportamentos iniciais de cooperação.

Não foram encontradas diferenças significativas entre os escores de altruísmo das crianças dos grupos que apresentaram ou não comportamento voltado para o parceiro. Não foram observadas diferenças de idade entre os que cooperam ou não e não houve relação com o sexo das crianças ou com escores das mães nas variáveis estudadas. Deste modo, nossa expectativa de relação entre os dois tipos de desenvolvimento não foi confirmada.

\section{Altruísmo}

Em geral, o grupo de crianças testadas não discriminou a situação de teste do controle. Em comparações pareadas da primeira tarefa de teste com o controle respectivo, não foram observadas diferenças significativas. Na segunda tarefa de teste, embora as crianças tenham apresentado, em média, mais respostas na situação de ajuda do que na de controle, o resultado do teste $t$ pareado também não foi significativo. Esse resultado não era esperado, difere das evidências de Warneken e Tomasello $(2006,2007,2009)$ e não apoiou nossa hipótese de que as crianças seriam capazes de discriminar situações em que sua ajuda é necessária daquelas em que não é.

Calculou-se, então, para cada criança, um "escore de altruísmo", a partir da soma das diferenças entre teste-controle nas duas situações. A média das respostas de comportamentos altruístas foi 6,03 $(D P=6,05)$. Foi encontrada uma correlação positiva entre metas relacionais e altruísmo $(r=0,41, p<0,05)$. Mães com maior valorização da interdependência têm filhos que apresentam maior frequência de comportamentos altruístas. Ainda que sejam incipientes os resultados referentes a comportamento altruísta nas crianças deste grupo, seu desempenho mostrou relação com a valorização de práticas relacionais pelas mães. Deste modo, há algum suporte para nossa quarta hipótese de relação entre os tipos de crenças maternas e o desempenho das crianças nas tarefas de cooperação e altruísmo.

\section{CONSIDERAÇÕES FINAIS}

O modelo de self autônomo-relacionado foi o privilegiado pelas mães participantes dessa investigação. Assim como em vários outros estudos brasileiros (Seidl-de-Moura, Carvalho, \& Vieira, 2013; Mendes \& Seidl-de-Moura, 2013) foi encontrada tendência mista, tanto para a valorização de autonomia quanto para proximidade interpessoal nas metas de socialização das mães. No que concerne a suas práticas, no entanto, houve predominância da autonomia, sendo que quanto mais eram valorizadas práticas de autonomia, menos as relacionais eram valorizadas e vice-versa. Tais resultados chamam a atenção para o fato de que embora as metas de socialização orientem práticas de cuidado, não necessariamente são totalmente aderentes a elas, no sentido de terem que convergir para o mesmo foco. Muitas vezes as pessoas agem de modo diverso de metas estabelecidas. Além disso, nossos estudos têm indicado que, mesmo com essa tendência geral de autonomia-relacionada, existe uma dinâmica 
na relação entre os dois aspectos que sofre influência de variáveis diversas, como a escolaridade, tal como ocorreu neste grupo de mães.

Os resultados sobre cooperação e altruísmo não foram totalmente como esperado. Parte do grupo foi capaz de ação conjunta visando uma meta comum, porém mais da metade não foi. A faixa etária do grupo de participantes foi pequena, o que pode explicar a ausência de relação entre o desempenho nas tarefas e idade.

De toda forma, uma vez que a criança apresente a capacidade de agir de modo altruísta, isto pareceu estar correlacionado a metas maternas de socialização, pois, segundo os resultados, quanto maior o escore das crianças em altruísmo mais as mães apresentaram metas de socialização priorizando a relação com outras pessoas. A partir dessas evidências é possível inferir que crianças educadas com metas de socialização que valorizem relacionamentos proximais, tendam a ser mais altruístas.

Algumas dificuldades foram encontradas na realização do estudo. A natureza da tarefa de cooperação, que exigia a participação de duas crianças, o tamanho e a pouca portabilidade do aparato determinaram que a coleta fosse realizada em creches. $\mathrm{O}$ número de creches que aceitaram participar da pesquisa foi reduzido, apenas três no total e, com isso, o $\mathrm{N}$ ficou relativamente pequeno. Além disso, apesar de solicitada a presença na sala de testagem de uma das educadoras das creches, isso nem sempre era possível, devido à rotina das instituições. Em consequência, membros do grupo de pesquisa faziam uma ambientação com as crianças e as levavam de suas salas para as de testagem. Muitas crianças choravam e não quiseram participar. Nesses casos, a testagem não era realizada com aquela criança. Os pais também relutavam em aceitar a participação, pois isso exigia que preenchessem e devolvessem questionários. Quando aceitavam e assinavam o termo de consentimento, e as crianças não tinham dificuldades em realizar as tarefas, muitas vezes os pais não disponibilizavam horário para a coleta de dados dos instrumentos que deveriam preencher.

Todas essas dificuldades contribuíram para limitações do estudo que podem ter levado à não confirmação de todas as hipóteses formuladas. Talvez por essas limitações, o estudo pode não ter testado adequadamente a relação entre as trajetórias de socialização priorizadas pelas mães e o desenvolvimento da cooperação e altruísmo em seus filhos. Hipotetizase, com base na teoria que, sendo o desenvolvimento um produto da interação com o contexto (Keller, 2007), e que em trajetórias de desenvolvimento diversas sejam priorizados diferencialmente aspectos desse desenvolvimento, deve haver relação entre os aspectos analisados neste estudo. Novas investigações, com diferentes tarefas de cooperação, que exijam aparatos mais simples e que possam ser realizadas em outros ambientes e com maior número de participantes, necessitam ser realizadas. Considera-se que este estudo exploratório traz uma contribuição para o planejamento dessas futuras investigações, visando melhor compreensão dessas dimensões da parentalidade e do desenvolvimento sociocognitivo infantil.

\section{REFERÊNCIAS}

Brownell, C. A., Ramani, G. B., \& Zerwas, S. (2006). Becoming a partner with peers: cooperation and social understanding in one- and two-years-olds. Child Development, 77(4), 803-821. http://dx.doi.org/10.1111/j.1467-8624.2006.00904.x

Hamlin, J. K., \& Wynn, K. (2011). Young infants prefer prosocial to antisocial others. Cognitive Development, 26, 30-39. http://dx.doi.org/10.1016/j.cogdev.2010.09.001

Keller, H. (2007). Cultures of Infancy. London: Lawrence Erlbaum Associates.

Keller, Lamm, Abels, Yovsi, Borke, Jensen et al. (2006). Cultural models, socialization goals, and parenting ethnotheories: A multi-cultural analysis. Journal of Cross-Cultural Psychology, 37(2), 155-172. http://dx.doi. org/10.1177/0022022105284494

Mendes, D. M. L. F. \& Seidl-de-Moura, M. L. (2013). O envelope narrativo e o desenvolvimento do self. Interação em Psicologia, 17(1), 37-46.

Seidl-de-Moura, M. L., Carvalho, R. V. C., Vieira, M. L. (2013). Brazilian mothers cultural models: Socialization for autonomy and relatedness. In: Maria Lucia Seidl-de-Moura. (Org.). Parenting in South American and African contexts.

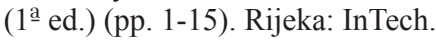

Schöre, A. N. (1994). Affect regulation and the origin of the self: the neurobiology of emotional development. Hillsdale, NJ: Lawrence Erlbaum Associates.

Svetlova, M., Nichols, S. R., \& Brownell, C. A. (2010). Toddlers' prosocial behavior: from instrumental to empathic to altruistic helping. Child Development, 81(6), 1814-1827. http://dx.doi.org/10.1111/j.1467-8624.2010.01512.x 
Tomasello, M. (2001). The cultural origins of human cognition. Cambridge, Mass.: Harvard University Press.

Tomasello, M., Melis, A., Tennie, C., Wyman, E., \& Herrmann, E. (2012). Two key steps in the evolution of human cooperation. Current Anthropology, 53(6), 673-692. http://dx.doi.org/10.1086/668207

Warneken, F. (2010, Outubro). On the origins of altruism in ontogeny and phylogeny. Palestra apresentada no Boston University Dialogues on Biological Anthropology, Boston, MA.

Warneken, F. (2013). Young children proactively remedy unnoticed accidents. Cognition, 126(1), 101-108. http://dx.doi. org/10.1016/j.cognition.2012.09.011

Warneken, F., Chen, F., \& Tomasello, M. (2006). Cooperative Activities in Young Children and Chimpanzees. Child Development, 77(3), 640-663. http://dx.doi.org/10.1111/j.1467-8624.2006.00895.x

Warneken, F., Gräfenhain, M., \& Tomasello, M. (2012). Collaborative partner or social tool? New evidence for young children's understanding of joint intentions in collaborative activities. Developmental Science, 15(1), 54-61. http:// dx.doi.org/10.1111/j.1467-7687.2011.01107.x

Warneken, F. \& Tomasello, M. (2006). Altruistic helping in human infants and young chimpanzees. Science, 311(5765), 1301-1303. http://dx.doi.org 10.1126/science.1121448

Warneken, F. \& Tomasello, M. (2007). Helping and Cooperation at 14 Months of Age. Infancy, 11(3), 271-294. http:// dx.doi.org/10.1111/j.1532-7078.2007.tb00227.x

Warneken, F. \& Tomasello, M. (2008). Extrinsic rewards undermine altruistic tendencies in 20-month-olds. Developmental Psychology, 44(6), 1785-1788. http://dx.doi.org/10.1037/a0013860

Warneken, F. \& Tomasello, M. (2009). The roots of human altruism; British Journal of Psychology, 100, 455-471. http:// dx.doi.org/10.1348/000712608X379061

\begin{abstract}
Autores:
Endereço para correspondência:

Maria Lucia Seidl de Moura

Rua Fritz Feigl, 465 - Jacarepagua

CEP 22750-600 Rio de Janeiro, RJ, Brasil

E-mail: mlseidl@gmail.com
\end{abstract}

MARIA LuCIA SEIDl DE Moura - Doutora, Universidade do Estado do Rio de Janeiro

Luciana Fontes PessôA - Doutora, Pontifícia Universidade Católica do Rio de Janeiro.

Deise MARIA LEAL FERnANDES MENDES - Doutora, Universidade do Estado do Rio de Janeiro.

RAFAEl VERA CRUZ DE CARVAlHo - Doutor, Universidade do Estado do Rio de Janeiro.

LAURA CRISTINA STOBÄUS - Doutora, Universidade do Estado do Rio de Janeiro.

Recebido em: 20.05.14

Aceito em: 24.11 .14 